\title{
Critiquing the Mathematical Literacy Assessment Taxonomy: Where is the Reasoning and the Problem Solving?
}

\author{
Hamsa Venkat ${ }^{1}$ \\ Mellony Graven ${ }^{2}$ \\ Erna Lampen ${ }^{1}$ \\ Patricia Nalube ${ }^{1}$ \\ ${ }^{1}$ Marang Centre for Mathematics and Science Education, Wits University \\ hamsa.venkatakrishnan@wits.ac.za; christine.lampen@wits.ac.za; patricia.nalube@wits.ac.za \\ ${ }^{2}$ Rhodes University \\ m.graven@ru.ac.za
}

\begin{abstract}
In this paper we consider the ways in which the Mathematical Literacy (ML) assessment taxonomy provides spaces for the problem solving and reasoning identified as critical to mathematical literacy competence. We do this through an analysis of the taxonomy structure within which Mathematical Literacy competences are assessed. We argue that shortcomings in this structure in relation to the support and development of reasoning and problem solving feed through into the kinds of questions that are asked within the assessment of Mathematical Literacy. Some of these shortcomings are exemplified through the questions that appeared in the 2008 Mathematical Literacy examinations. We conclude the paper with a brief discussion of the implications of this taxonomy structure for the development of the reasoning and problem-solving competences that align with curricular aims. This paper refers to the assessment taxonomy in the Mathematical Literacy Curriculum Statement (Deparment of Education (DOE), 2007).
\end{abstract}

Mathematical Literacy was introduced as a new subject in the post-compulsory Further Education and Training (FET) curriculum in 2006. Its introduction made a mathematically-oriented subject - either Mathematics or Mathematical Literacy - compulsory for all FET learners. The curriculum statement for Mathematical Literacy defines the subject in the following terms:

Mathematical Literacy provides learners with an awareness and understanding of the role that mathematics plays in the modern world. Mathematical Literacy is a subject driven by life-related applications of mathematics. It enables learners to develop the ability and confidence to think numerically and spatially in order to interpret and critically analyse everyday situations and to solve problems. (DOE, 2003, p. 9)

This definition alongside the broader description of the new subject's aims in this document places emphasis on the need to develop life-oriented competences for a range of everyday situations in which mathematical reasoning and mathematical tools can be brought to bear productively to aid informed decision making and problem solving. Situational reasoning relating to the identification and selection of salient features of the context is therefore required alongside and integrated with mathematical reasoning. 
Within this definition, we highlight two features that the broader literature suggests are central to the notion of mathematical literacy that is promoted in the South African rhetoric: firstly, the need for the reasoning that is implicated within the need to "think numerically and spatially" and to "interpret" and "critically analyse everyday situations"; and secondly, the need for "problem solving". Both of these aspects have significant bodies of literature associated with them in the field of mathematics education some focused on the teaching and learning of mathematics, and some specific to discussions of mathematical literacy. Olkin and Schoenfeld (1994), focusing on mathematics, describe problem solving in terms of "confronting a novel situation and trying to make sense of it" (p. 43).

Steen, a leading advocate of what he terms "quantitative literacy" comments that centrally what quantitatively literate citizenship requires is "a predisposition to look at the world through mathematical eyes ... and to approach complex problems with confidence in the value of careful reasoning" (Steen, 2001, p. 2).

In both of these quotations - across mathematics and mathematical literacy - reasoning and problem solving are seen to involve complex problems/novel situations. Further, Steen's viewpoint suggests that "complex problems" are essential to developing mathematical literacy as a life-oriented competence.

In this paper our focus is on exploring the extent to which reasoning and problem solving as described in the literature (Halmos, 1975; Polya, 1962; Steen, 2001) and in the rhetoric of international parallels to ML (e.g., Functional Mathematics in England) figure within the assessment of ML in South Africa. The results of the first ML examinations within the new FET National Senior Certificate (taken in 2008 in which $79 \%$ of the cohort attained a 'pass' or above $(\geq 30 \%)$ ) were met with some scepticism in public commentaries (e.g., Jansen, 2009). Earlier in 2008, academic critiques had already raised concerns that the exemplar papers for ML did not appear to align well with the taxonomy against which assessments were supposed to be designed, with an overrepresentation of questions focused on the lower levels (Prince, Frith, \& Burgoyne, 2008).

This taxonomy, provided in the Subject Assessment Guidelines (SAG) document (DOE, 2007), is outlined in the following terms, with guideline percentages given for the distribution of marks across its levels in ML assessments:

\section{Level 1: Knowing (30\% of marks)}

Level 2: Applying routine procedures in familiar contexts (30\%)

Level 3: Applying multi-step procedures in a variety of contexts $(20 \%)$

Level 4: $\quad$ Reasoning and reflecting $(20 \%)$

Prior analyses have considered the 2008 ML examination papers in relation to this taxonomy (Umalusi, 2009), and pointed to an over-representation of lower level questions in Paper 2 specifically. Paper 2, according to the specification in the SAG document, should focus predominantly on Level 3 and Level 4, with a small proportion of marks allocated to Level 2 whilst Paper 1 focuses solely on Levels 1 and 2.

Given these analyses, our aim in this paper is to consider more specifically whether the taxonomy provides sufficient openings for developing what the literature base identified above tells us are key competences for becoming mathematically literate citizens - competences that are also highlighted in the rhetoric of the South African ML curriculum statement.

In order to facilitate our consideration of this issue, we have structured this paper as follows. We begin with a brief review of literature that point to reasoning and problem solving as critical to the notion of mathematical literacy. We then go on to consider the taxonomy structure in some detail, and locate the areas and levels within which reasoning and problem solving are assessed, and the ways in which other competences figure alongside these. We argue that shortcomings in this structure in relation to the support and development of reasoning and problem solving feed through into the kinds of questions that can be asked within the assessment of ML. These shortcomings are exemplified through the questions that appeared in the $2008 \mathrm{ML}$ examinations. We conclude the paper with a brief discussion of the implications

\footnotetext{
1 We use the capitalised "Mathematical Literacy" to refer to the South African subject specification and its enactments, and the small "mathematical literacy" to refer to a more generalised notion of a life-related competence that has a significant literature base associated with it in the field of mathematics education.
} 
of this taxonomy structure for the development of the reasoning and problem-solving competences that align with curricular aims. Specifically, we relate this discussion to how we interpret students' performance in the $2008 \mathrm{ML}$ examination.

\section{Essential competences for mathematical literacy}

One of the difficulties in trying to identify essential competences for mathematical literacy is the fact that a range of interpretations exist as to what mathematical literacy actually is. In her analysis of a range of perspectives on mathematical literacy, Jablonka notes that even the notion of essential competences "transferable methodological and process skills" (2003, p. 79) in her terms - is only possible within particular conceptions of what mathematical literacy is about. She argues that the centrality of problem solving and reasoning are emphasised in the view of mathematical literacy embodied in the definition and problems set within the international comparison oriented Program for International Student Assessment (PISA) tests for example (Organisation for Economic Cooperation and Development (OECD), 2003). She points out the imperatives for standardisation across cultures and measurement of competence within these tests, and argues that these imperatives take precedence over the need for genuine relevance. Of interest in the South African ML context is the explicit acknowledgement of the OECD conception of mathematical literacy and its associated view of development in mathematical literacy competence within the development of the South African ML taxonomy. This suggests that reasoning and problem-solving development will be central to the assessment framework.

Further insights on the nature of the problem solving needed for mathematical literacy is provided within the documentation associated with the introduction of Functional Mathematics as a new subject in England. The definition of Functional Mathematics in England overlaps in significant ways with the South African definition of ML, containing phrases such as these:

Functional mathematics requires learners to be able to use mathematics in ways that make them effective and involved as citizens, able to operate confidently in life and to work in a wide range of contexts. ( Qualifications and Curriculum Development Agency, 2007, p. 19)

Problem solving is stressed as a key feature of being able to use mathematics in functional ways, with some detail provided on the ways in which problems should be presented in order to aid the development of a functional competence:

It is important that learners are not told, at the time a problem is set, which of the mathematical tools they have at their disposal will actually be needed. Selecting the right tools is a core aspect of becoming functional in mathematics. (Functional Skills Support Programme, 2007, pp. 22-23)

And further:

It is very important for learners to experience the need to decide for themselves whether a problem can be addressed using mathematics, what mathematics might help, and how the problem should be set out mathematically. (Functional Skills Support Programme, 2007, p. 24)

The importance of the lack of "obvious-ness" of solution routes in order for genuine problem solving to occur has also been repeatedly emphasised within the mathematics education literature:

...to have a problem means: to search consciously for some action appropriate to attain a clearly conceived, but not immediately attainable, aim. To solve a problem means to find such action. (Polya, 1962, p. 117)

A further feature of this kind of problem solving in which the solution route is not immediately obvious is the importance of problem-posing, of asking questions that are appropriate to the context of the problem:

The hardest part of answering questions is to ask them. [...] the chief problem is likely to be "what is the problem?". Find the right question to ask, and you're a long way toward solving the problem you're working on. (Halmos, 1975, pp. 466-467) 
We argue that, both in mathematics and in mathematical literacy, the processes of problem-posing and problem-solving require reasoning in a range of ways - in asking the right questions, in choosing the mathematical tools that might assist in answering them, in selecting the most appropriate ways of representing information using these tools, in working systematically, and in analysing and interpreting results in context (with contexts usually drawn intra-mathematically in mathematics and from real life situations in ML). An important feature of this view of reasoning is the way in which it permeates the problem-solving process, rather than following the problem-solving process. We return to this point when we consider the South African Mathematical Literacy taxonomy in the following section.

In the English Functional Mathematics specification, four features of "level differentiation" are outlined for describing problem demand in the sphere of contextualised problems:

o the complexity of the situation

$\circ$ the familiarity to the learner of the situation or problem

0 the technical demand of the mathematics required

0 the independence of the learner in tackling the situation or problem.

(Functional Skills Support Programme, 2007, p. 25)

This model of complexity differs from the South African ML taxonomy in important ways. In the next section, we consider the outline and specification of this taxonomy in some detail.

\section{The Mathematical Literacy taxonomy}

The headings of the four levels of the ML taxonomy, presented in the introduction, suggest two overt strands that vary across the levels: a mathematical strand evident within the reference to "knowing" (mathematical facts) at Level 1 and moving to the use of increasingly complex (or at least lengthy) procedures (Levels 2 and 3); and a contextual strand that moves from "familiar" contexts (Level 2) to a "variety of contexts" (Level 3).

Combining content (in terms of facts and procedures) and context oriented complexity within a single hierarchy appears to suggest that both these aspects become more complex together. This contrasts with the view presented in Functional Mathematics in the last section where the categories suggest that these can vary independently of each other, with "technical demand of the mathematics" providing one avenue for making problems more demanding, and "complexity of the situation" providing another avenue.

A further feature at the outline level is that recall of fact and engagement with mathematical procedures is followed by "reasoning and reflecting" at Level 4. In the section above and in earlier writing (Venkat, Graven, Lampen, Nalube, \& Chitera, 2009), we have commented that this "deferral" of reasoning construed as following the "doing" of mathematics - is problematic from the perspective of the literature outlined on what it means to be mathematically literate.

The Subject Assessment Guidelines document provides descriptions of each of the taxonomy levels in Figure 1 (DOE, 2007, pp. 27-28).

Given our focus on reasoning and problem solving as central competences that need to be developed for mathematical literacy, it was instructive to start by looking for where these features occurred within the assessment taxonomy. In the terms outlined in our literature review, problem solving appears to figure only at Level 3 (AMP1). Whilst there is reference to problem solving at Level 2 (ARP1), the emphases on the "obvious-ness" of the procedure that is needed and the immediate availability of all the required information would tend to disqualify this reference in the terms outlined in the literature on problem solving. Problem-posing, in the ways referred to within our overview of the literature, figures only at Level 4. 


\begin{tabular}{|c|c|c|c|}
\hline Level 1: Knowing $(\mathrm{K})^{2}$ & $\begin{array}{l}\text { Level 2: Applying routine } \\
\text { procedures in familiar contexts } \\
\text { (ARP) }\end{array}$ & $\begin{array}{l}\text { Level 3: Applying multi-step } \\
\text { procedures in a variety of } \\
\text { contexts (AMP) }\end{array}$ & $\begin{array}{l}\text { Level 4: Reasoning and } \\
\text { reflecting (RR) }\end{array}$ \\
\hline $\begin{array}{l}\text { Tasks at the knowing } \\
\text { level of the ML } \\
\text { taxonomy require } \\
\text { learners to: } \\
\text { K1 Calculate using the } \\
\text { basic operations including: } \\
\text { o algorithms for +, -, } \times \text {, } \\
\text { and } \div \text {; } \\
\text { o appropriate rounding of } \\
\text { numbers; } \\
\text { o estimation; } \\
\text { o calculating a percentage } \\
\text { of a given amount; and } \\
\text { o measurement } \\
\text { K2 Know and use } \\
\text { appropriate vocabulary } \\
\text { such as equation, formula, } \\
\text { bar graph, pie chart, } \\
\text { Cartesian plane, table of } \\
\text { values, mean, median and } \\
\text { mode. } \\
\text { K3 Know and use } \\
\text { formulae such as the area } \\
\text { of a rectangle, a triangle } \\
\text { and a circle where each of } \\
\text { the required dimensions is } \\
\text { readily available. } \\
\text { K4 Read information } \\
\text { directly from a table (e.g. } \\
\text { the time that bus number } \\
1234 \text { departs from the } \\
\text { terminal). }\end{array}$ & $\begin{array}{l}\text { Tasks at the applying routine } \\
\text { procedures in familiar contexts } \\
\text { level of the ML taxonomy require } \\
\text { learners to: } \\
\text { ARP1 Perform well-known } \\
\text { procedures in familiar contexts. } \\
\text { Learners know what procedure is } \\
\text { required from the way the } \\
\text { problem is posed. All of the } \\
\text { information required to solve the } \\
\text { problem is immediately available } \\
\text { to the student. } \\
\text { ARP2 Solve equations by means } \\
\text { of trial and improvement or } \\
\text { algebraic processes. } \\
\text { ARP3 Draw data graphs for } \\
\text { provided data. } \\
\text { ARP4 Draw algebraic graphs for } \\
\text { given equations. } \\
\text { ARP5 Measure dimensions such } \\
\text { as length, weight and time using } \\
\text { appropriate measuring } \\
\text { instruments sensitive to levels of } \\
\text { accuracy. }\end{array}$ & $\begin{array}{l}\text { Tasks at the applying multi- } \\
\text { step procedures in a variety of } \\
\text { contexts level of the ML } \\
\text { taxonomy require learners to: } \\
\text { AMP1 Solve problems using } \\
\text { well-known procedures. The } \\
\text { required procedure is, } \\
\text { however, not immediately } \\
\text { obvious from the way the } \\
\text { problem is posed. Learners } \\
\text { will have to decide on the most } \\
\text { appropriate procedure to solve } \\
\text { the solution to the question } \\
\text { and may have to perform one } \\
\text { or more preliminary } \\
\text { calculations before } \\
\text { determining a solution. } \\
\text { AMP2 Select the most } \\
\text { appropriate data from options } \\
\text { in a table of values to solve a } \\
\text { problem. } \\
\text { AMP3 Decide on the best } \\
\text { way to represent data to create } \\
\text { a particular impression. }\end{array}$ & $\begin{array}{l}\text { Tasks at the reasoning } \\
\text { and reflecting level of the } \\
\text { ML taxonomy require } \\
\text { learners to: } \\
\text { RR1 Pose and answer } \\
\text { questions about what } \\
\text { mathematics they require } \\
\text { to solve a problem and } \\
\text { then to select and use that } \\
\text { mathematical content. } \\
\text { RR2 Interpret the } \\
\text { solution they determine to } \\
\text { a problem in the context } \\
\text { of the problem and where } \\
\text { necessary to adjust the } \\
\text { mathematical solution to } \\
\text { make sense in the context. } \\
\text { RR3 Critique solutions to } \\
\text { problems and statements } \\
\text { about situations made by } \\
\text { others. } \\
\text { RR4 Generalise patterns } \\
\text { observed in situations, } \\
\text { make predictions based on } \\
\text { these patterns and/or other } \\
\text { evidence and determine } \\
\text { conditions that will lead } \\
\text { to desired outcomes. }\end{array}$ \\
\hline
\end{tabular}

Figure 1: Description of the Mathematical Literacy assessment taxonomy levels

Given then that problem solving (using well-known procedures) makes an appearance only at Level 3, with reasoning deferred to Level 4, we then began to look across the levels at the ways in which complexity appeared to be conceptualised within the taxonomy. We were able to discern four threads relating to mathematical development within the structure, with other aspects appearing in much more localised ways within particular levels. The developmental threads we identified are as follows:

$\circ$ calculation/procedure

$\bigcirc$ algebraic competence

$\circ$ dealing with tabulated information

$\circ$ knowledge and competence in data representation

In the following sections we discuss each of these developmental threads, and then go on to identify aspects that appear in more "singular", non-developmental ways within the taxonomy structure.

\footnotetext{
${ }^{2}$ Abbreviation of level headings and numbering of aspects within levels added by us to facilitate reference.
} 


\section{Calculation/procedure}

Across the four levels of the taxonomy, there is recurring reference to calculations and procedures. At the most basic level, the four taxonomy labels indicate that development within this thread proceeds along the lines of knowledge/recall of procedure (K), application of routine procedures (ARP), application of multistep procedures (AMP), identifying the appropriate questions to ask in order to identify procedures to solve problems using mathematics as a tool (RR).

Whilst this labeling indicates a rather mathematically-based progression across levels, closer reading of the descriptions indicates that such mathematically-oriented progression is intertwined with the following three sub-threads:

- The degree of "known-ness" of the procedure to be applied

- The degree of "immediate availability" of the information required to use the procedure to solve the problem

○ The degree of "obvious-ness" around what procedure to use

We now discuss each sub-thread in turn.

\section{Degree of "known-ness" of the procedure to be applied}

The descriptions across the levels point to a progression from "basic operations" to "well-known procedures" to "identification of" an appropriate mathematical procedure, which may also be well-known or even basic. The listing of basic arithmetical operations under K1 suggests that a school mathematics curriculum hierarchy of procedure may underlie the way progression within this sub-thread is interpreted. As such, there is an overlap between this sub-thread and the notion of the "technical demand of the mathematics" that is presented as one variable within problem demand in Functional Mathematics.

\section{Degree of "immediate availability" of the information required to use the procedure to solve the problem.}

The descriptions under ARP1 and AMP1 allude to this as a developmental sub-thread of application of procedures. The lack of any allusion to contextualisation under K1 suggests that required information may be directly given within decontextualised questions - a suggestion confirmed by the presence of such questions in Paper 1 in the 2008 ML examination, in spite of advice to teachers to avoid this practice in the SAG: "When teaching and assessing Mathematical Literacy, teachers should avoid teaching and assessing mathematical content in the absence of context" (DOE, 2007, p7).

\section{Degree of "obvious-ness" around what procedure to use}

Comments within the descriptions for ARP1 and AMP1 suggest that this factor represents a key discriminator between Level 2 and Level 3 questions. When combined with the lack of contextualisation in some Level 1 questions, this sub-thread relates to the degree of explication of specific procedures in the statement of the question. This suggests that at Levels 1 and 2, direct pointers towards the required mathematics are acceptable, resulting in heavily scaffolded questions in the examination papers that emphasise and test calculation skills, thus vitiating the assessment of problem solving.

Several interesting issues are raised within the calculation/procedure developmental thread and the subthreads within it in the context of the South African ML curriculum. First there is the mathematical orientation of the progression - a feature that appears to contradict the curriculum specification within which overt mathematical progression is limited, and explicitly acknowledged:

For Mathematical Literacy, the Assessment Standards do indicate progression from grade to grade. However, this progression is not markedly evident in some of the Assessment Standards. The complexity of the situation to be addressed in context, through using the mathematical knowledge and ways of thought available to the learner, is where the extent of the progression needs to be ensured. (DOE, 2003, p. 38)

The framing of progression in terms of mathematical procedure within the taxonomy is somewhat problematic. We acknowledge and accept that this progression is both a necessary and useful part of the frame of mathematical literacy development - that recognising and unpacking mathematical progression within the context of problem solving provides both rationales for mathematical development and a range of increasingly sophisticated tools for making sense of situations. However, to allow mathematical 
progression to dominate the assessment of a curriculum that is oriented towards quantitative and mathematical reasoning for life-situations appears akin to the "tail wagging the dog" and runs the risk of diminishing the emphasis on understanding everyday contexts that is central to the curriculum rhetoric.

Secondly, the progression appears to move from an emphasis on basic arithmetical procedure into directed straightforward procedures, and then onto less directed and more complex procedures. The calculating thread therefore appears to build in procedural complexity alongside a "degree of explication" strand, with procedures getting more complex and diminishing explication of the procedure to use occurring together. This suggests that these two features cannot be varied independently. This view tends to contradict Steen's position that quantitative literacy more often involves "real data and uncertain procedures but require[s] primarily elementary mathematics" (Steen, 2001, p. 6).

Here, Steen's view suggests that a diminishing degree of explication - again related to the degree of scaffolding - of specific procedures ought to be an overarching development thread in order to meet the goals of mathematical literacy, with limited shifts towards more complex procedures.

The shift from a directed emphasis on basic calculation towards the selection and use of mathematical tools within a problem-solving frame correlates with what has been presented by some writers as a potential model of how sophistication builds up in mathematical literacy. Maguire and O'Donoghue (2003) present an "organising framework" for numeracy within which numeracy builds from a "formative phase" with an emphasis on arithmetic skills, into a "mathematical phase" in which the mathematics in everyday situations is made explicit, and then into an "integrative phase" where mathematics, communication and culture have to be synthesised in context. This view though, tends to be contradicted by findings in mathematics education located within a situated learning perspective (Boaler, 1997; Scribner, 1984). Both these studies suggest that people can become good (efficient and effective) at activities that they practise - designing efficient distribution schedules in Scribner's case and non-routine, mathematics problems in Boaler's case. Given that the taxonomy allows for $60 \%$ of the marks in ML assessments, even at Grade 12 level, to come from basic arithmetic and simple calculation without involving reasoning or problem solving in context, our concern is that there simply is not enough pressure to infuse ML learning with these latter features. Instead, the mathematical calculation thread allows for procedural mathematics to dominate in ways that often work against the aims of the curriculum.

\section{Algebraic competence}

This developmental thread appears somewhat incongruous when considered alongside the advocacy in policy documents for work in ML to be led by the need to "engage with contexts rather than applying Mathematics already learned to the context" (DOE, 2003, p. 42) - given that the emphasis appears to be on mathematically focused progression located within one particular domain of mathematics - algebra. Once again, whilst there are stronger indications here of an algebraically focused interpretation of progression, i.e. knowledge and use of formulae (K3) to solving equations algebraically (ARP2) or drawing algebraic graphs for equations (rather than situations) (ARP4) to generalising patterns in context (RR4), statements incorporate the degree of immediacy of information needed to apply algebraic tools as part of the increasing complexity of problems (e.g., K3).

\section{Dealing with tabulated information}

Information presented in tabular form curiously seems to receive special attention within the taxonomy, rather than a more general competence in dealing with numerical information from a variety of sources and representations (including graphs and written text) that is often highlighted in literature dealing with the nature of mathematical or quantitative literacy (e.g., Steen, 2001). Progression within this developmental thread appears to be delineated primarily in terms of the degree of interpretation needed to "select" appropriate information from a table in order to answer a question or solve a problem. Thus, at the knowing level, the information needed can be found "directly" from the question in the table provided (K4), whilst a higher level competence in this strand would require some interpretation in order to select the "most appropriate data from options in a table" (AMP2). The notion of immediacy is therefore present within this thread as well. 


\section{Knowledge and competence in data representation}

The hierarchy presented in this developmental thread appears to suggest that low level competence is evident in knowledge and use of some basic representations (bar charts, introduced in the foundation phase content mathematics curriculum), are mentioned specifically - K2). This proceeds into an unspecified drawing of "data graphs for provided data" (ARP3), and then into a more critical engagement with the kinds of data presentation that might support specific positions or arguments (AMP3). Critiquing provided data presentations can potentially fall within the remit of RR3, but is not indicated as the final progression of this thread. Within this thread too therefore, the "production" of mathematics prevails at Levels 1 and 2, with critical engagement appearing only at Level 3, implying that reasoning will not be assessed in the reading of tables or the drawing of graphs.

\section{Non-progressing descriptors}

This identification of developmental threads and some cross-cutting sub-threads leaves some aspects of the specification of the taxonomy as yet untouched. The "missing" descriptors appeared to us to stand in much more isolated ways within particular levels without a sense of progression attached to the skill or competence presented. Examples of this include the emphasis on measurement which appears in ARP5. Whilst this descriptor can be interpreted as following on from "given" dimensions which feature in K3, the activity of measuring appears at this point only and appears to qualify as a routine procedure regardless of the context of the actual measurement. Similarly, the need for "one or more preliminary calculations before determining a solution" (AMP1) appears to push a question into the third level irrespective of the actual calculations required. The practical consequence is that the stringing together of routine calculations is construed as indicative of a high level of mathematical literacy.

The key location for non-progressing descriptors though occurs within the "reasoning and reflecting" level. Problem posing and interpretation or adjustment of answers in context only figure at this level, with lower levels providing few, if any, handles for the development of this kind of reasoning and critique capacity. As stated earlier, we have expressed our concern that the taxonomy appears in this way to separate the "doing" of ML from the "reasoning" required for ML (Venkat et al., 2009). One consequence of this separation is that lower level reasoning skills are rendered invisible, for example in question 2.2.2 in Example 1 (see further on), which requires candidates to visualise where a maximum height occurs as the arms of a wind turbine circulate. Developing such visualisation skills is seen as an important component of reasoning for both mathematical literacy (de Lange, 1999) and for mathematics (Presmeg, 1986).

A second consequence is that, given that reasoning and reflecting is understood to "follow" the calculating of answers, reasoning questions tend to focus narrowly on rather limited interpretation and commentary on previously calculated answers. Question 2.4.3 in Paper 2, asking candidates to comment on whether a payment option involving a deposit and monthly instalments or one involving taking out a loan for an outright purchase is preferable, following step by step calculations for the previous steps provides a good example of this kind of limited interpretation demand. Essentially in this view, reasoning is reduced to a "reflection on prior calculation in context" - calculations that are so extensively scaffolded that the need for reasoning about the chain of steps required to make an informed decision is effectively removed.

In summary, two aspects occur recurrently in this analysis of the taxonomy - firstly, a tendency towards procedural orientations to progression in several of the threads, and secondly, the notion that the degree of "immediacy" of information availability and/or "explication" of the required mathematical tools provides a sub-thread contributing to mathematical progression. Key problems, in our view, relate firstly to the lack of a developmental thread across taxonomy levels related to openings for reasoning and problem solving, compounded by the interpretation of reasoning as a "deferred" activity understood in rather limited ways. Secondly, the emphasis on mathematically-oriented progression is problematic in assessing a curriculum that contains a limited degree of mathematical development in its specification. This tends to result in a somewhat arbitrary breakdown of procedures into taxonomy levels.

This breakdown is made much more explicit in the taxonomy version provided in the Examination Guidelines document which ML teachers are encouraged to use, in which, for example, calculating a 
percentage of a given quantity qualifies for a Knowing (K) level competence, whilst calculating a percentage increase or decrease of a given quantity falls with the Applying routine procedures (ARP) level. Anomalies result from this kind of breakdown in mathematical terms - a percentage reduction problem (e.g., to calculate the effect of reducing R400 by 12\%), can be calculated as $0,88 \times \mathrm{R} 400$ for a one-stage solution or as a two-stage solution by calculating the $12 \%$ amount and subtracting. The first route in procedural terms carries exactly the same technical demand as a Level 1 question, but some mathematical reasoning about the structure underlies this calculation. The second route makes the procedure 'longer' - and the emphasis on moving from "routine procedures" to "multi-step procedures" in the Level headings of the taxonomy suggests that it is this "length of procedure" orientation that prevails in the taxonomy, rather than the reasoning underlying the more efficient procedure. As such, the kind of reasoning that underlies the more efficient procedure in the first solution tends to remain invisible in the taxonomy frame. In turn, this invisibility makes it unlikely that such reasoning will be encouraged in ML classrooms.

In the next section, we compare three questions from the 2008 ML examinations which exemplify the problems we have identified in this section. The first example is from Paper 1 which aims to assess ML at Levels 1 and 2, while the other examples are from Paper 2, aimed at assessing ML at Levels 3 and 4.

\section{Questions from the 2008 Mathematical Literacy examinations}

Example 1-Paper 1, question 2.2

2.2 Electricity has become a scarce resource in South Africa. As a result the country is investigating alternative sources of generating electricity. One alternative source of generating electricity is a wind turbine using rotating blades as shown in the picture and diagram below.
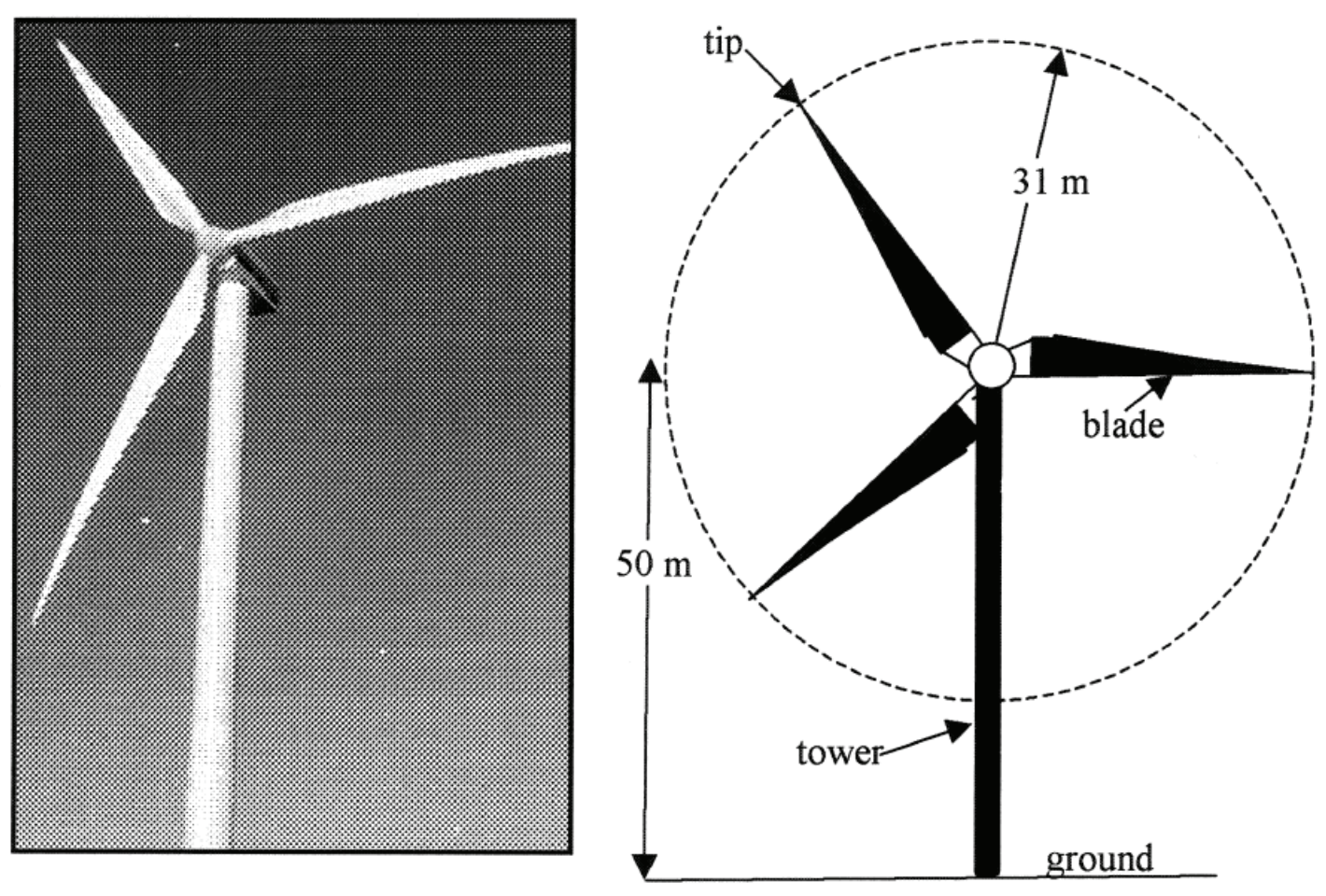

The wind turbine is mounted on the top of a $50 \mathrm{~m}$ high tower.

The length of each blade is $31 \mathrm{~m}$. 
2.2.1 What is the length of the diameter of the circle that the blades create as they rotate?

2.2.2 Calculate the maximum height from the ground that the tip of a blade will be, if the turbine is rotating.

2.2.3 Calculate the circumference of the circle made by the blades when they rotate.

(Circumference $=2 \times \pi \times$ radius), using $\pi=3,14$

2.2.4 Calculate the area of the circle made by the blades when they rotate.

$$
\left(\text { Area }=\pi \times(\text { radius })^{2}\right) \text {, using } \pi=3,14
$$

2.2.5 Suppose each household requires $25 \mathrm{~kW}$ of electricity daily.

If one wind turbine produces $1750 \mathrm{~kW}$ of electricity daily, calculate how many households could be provided daily with electricity from one such turbine.

\section{Commentary}

We note that within the second diagram given, a mathematical representation of the wind turbine is provided to candidates. This provision has several consequences. Firstly, the need to engage with the context through making sense of the photo representation of the wind turbine, and connecting this representation to the textual information given beneath it is diminished. The need to select the salient features of the context in order to create a mathematical model is therefore completely removed. Further, the reasoning load required to answer question 2.2.1 to 2.2.4 is also consequently reduced, although as we have pointed out, low-level visualising is still required to "imagine" the location of a blade to get the maximum height above ground (in spite of the fact that the taxonomy renders this invisible).

We argue that the lack of openings for problem representation, reasoning and problem solving in the formulation of questions such as this one follow from the structure of the taxonomy. Paper 1 is structured so that it contains only questions at Levels 1 and 2 of the taxonomy, and our analysis above indicates that neither reasoning nor problem solving are represented at these levels. Essentially therefore, given the mathematical model and the formulae needed for the circumference and area of a circle, the question becomes a test of the candidate's ability to calculate - again, in line with the orientation of the taxonomy, but much less in line with the spirit of the curriculum. 
2.4 Thandi decides to buy a dishwasher based upon the advertisement below.

Come to Best Buy Dealers for the best deals in town.

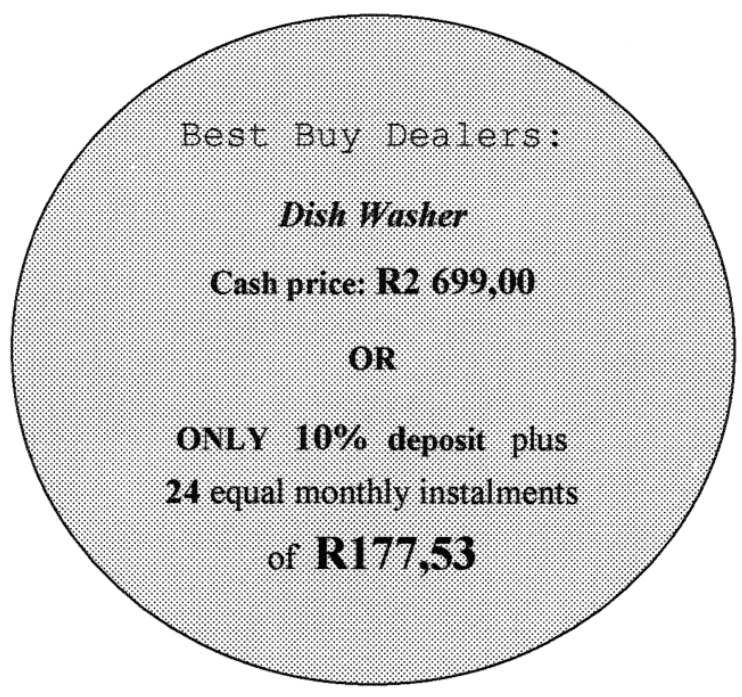

2.4.1 Suppose Thandi decides to buy the dishwasher using the instalment option.

(a) What is the balance owing after paying the deposit?

(b) Calculate the total cost of the dishwasher.

2.4.2 Suppose Thandi takes a loan from ABC Bank for the full cash price of the dishwasher. She is charged interest of $18 \%$ p.a. compounded monthly and agrees to repay the loan over two years in equal monthly instalments.

Use the formula $\mathrm{A}=\mathrm{P}(1+i)^{n}$ to calculate the total amount to be paid back, where:

$A=$ total amount to be paid back

$\mathbf{P}=$ loan amount

$i=$ monthly interest rate

$n=$ number of months over which the loan will be taken

2.4.3 Which method of payment would you advise Thandi to choose? Give a reason for your answer.

\section{Commentary}

Essentially this Paper 2 question asks candidates to calculate and then compare across the three options available (with sub questions directing each calculation), and to then select one and provide some kind of justification for it.

Questions such as 2.4.3, which asks candidates to look over a prior sequence of well structured calculations, and to justify a selection in some way from these appears to be the most common way in which "reasoning and reflecting" questions are incorporated into the ML examination. None of these skills appears to us to merit the conferral of a high level of reasoning in relation to mathematical literacy. However, given the lack of a developmental thread related to reasoning, and the scaffolding away of a more genuine orientation to problem solving, such questions are by default classified at Level 4 within the taxonomy. 
Example 3 - Paper 2, question 4.2

4.2 Lebo's family lives in the Eastern Cape. He now lives and works in Gauteng and earns a net salary of R10 625,00 per month. He sends home $35 \%$ of his net monthly salary every month and uses the rest for his own living expenses.

Lebo's living expenses include the following:

- R3 500,00 per month for food and rental

- R18,00 per day for transport (He works for 21 days every month.)

- A cellphone contract of R135,00 per month

- Clothing accounts of R250,00 a month

- $10 \%$ of his net monthly salary for entertainment

4.2.1 Complete Lebo's monthly budget on ANNEXURE C. Show ALL the calculations on ANNEXURE C.

(a) Calculate the amount he sends home every month. Fill in the answer at $\mathbf{A}$.

(b) Calculate the amount he has left for his own living expenses. Fill in the answer at $\mathbf{B}$.

(c) Calculate his total monthly living expenses.

Fill in the answer at $\mathbf{C}$.

(d) Calculate the amount he has left after all his monthly living expenses have been paid.

Fill in the answer at $\mathbf{D}$.

\section{Commentary}

This question is also drawn from Paper 2, which should be primarily constituted by tasks at Levels 3 and 4 of the taxonomy. The phrasing of the initial context in question 4.2 draws students into the reading of a relatively complex text, yet with all information explicitly provided. Much of the remaining complexity is removed by the structure of the sub-questions in question 4.2.1. We point out here the step by step nature of the scaffolding provided in question 4.2.1 in order to get to a value for how much Lebo has left in hand after expenses each month. As in the previous example, problem representation skills are reduced significantly through both the scaffolding and the provision of a table for collation, and each part of the question requires relatively directed and relatively basic calculation skills. The provision of Annexure C containing a table formatted to allow each of the expenses to be listed in rands and cents in a sensible order, completely removes the Level 3 requirement to "decide on the best way to represent data to create a particular impression."

As with the questions in Examples 1 and 2, we note the potential of this scenario to open up avenues for complex problem solving, but in the over-scaffolding that follows, much of the potential for decisionmaking and interpretation is removed. The difficulty essentially, therefore, lies not in the choice of problem contexts, but in the design of the questions within them, which seem to be designed to mimic the taxonomy in their unfolding.

\section{Conclusions}

Widespread evidence of assessment driving teaching (Clarke, 1996) indicates that the taxonomy upon which ML assessments are designed has implications for teaching. Our analysis of the taxonomy reveals that an emphasis on problem solving only really comes into play at Level 3 of the taxonomy and yet the 
literature and curriculum documents suggest that this is the crux of the aim of ML. The emphasis on routine calculations is marked overtly at Levels 1 and 2 - which by definition then, fall outside the realm of problem solving. Thus immediately visible from this taxonomy is the way in which the key aims of ML as given in the definition are located primarily in Levels 3 and 4. Indeed the definition of ML is that it is a subject driven by life related applications which enables learners to think numerically and spatially "in order to interpret [Level 3] and critically analyse [Level 4] everyday situations and to solve problems [Level 3]" (DOE, 2003, p. 9, emphasis and levels added). In relation to the specification that Paper 1 only includes questions at Level 1 and Level 2 of the taxonomy we have to question the validity of such a paper in assessing the aims of ML as given by the definition. As we have pointed out, some aspects of the literature point to difficulties with interpreting the basic calculation focus of Levels 1 and 2 as an appropriate lead in to service the problem solving and reasoning demands of Levels 3 and 4.

Furthermore if across the two papers $60 \%$ of the marks can be obtained without any problem solving, mathematical interpretation and reasoning, then again the validity of what a 'pass' in this subject means in relation to the curriculum statement is called into question. In this respect the very high pass rate in mathematical literacy is unsurprising. Perhaps what it indicates is that $79 \%$ of all learners who wrote the examination were able to perform/demonstrate basic mathematical operations, calculations/ skills and apply them to some extent in familiar situations where the necessary procedure is relatively obvious from the information given (which is immediately available). Perhaps the proportion of learners who received more than $60 \%$ for the examination is a better reflection of those who were able to demonstrate some competence in meeting what the curriculum rhetoric suggests as requirements to be mathematically literate.

\section{References}

Boaler, J. (1997). Experiencing school mathematics: Teaching styles, sex and setting. Buckingham: Open University Press.

Clarke, D. (1996). Assessment. In A. J. Bishop, K. Clements, C. Keitel, J. Kilpatrick, \& C. Laborde (Eds.), International handbook on mathematics education (pp. 327-370). Dordrecht: Kluwer Academic Publisher.

de Lange, J. (1999). Framework for classroom assessment in mathematics. Utrecht: Freudenthal Institute \& the National Center for Improving Student Learning and Achievement in Mathematics and Science. Available from http://www.fi.uu.nl/catch/products/framework/de_lange_frameworkfinal.pdf.

Functional Skills Support Programme. (2007). Resources to support the pilot of functional skills: Teaching and learning functional mathematics. London: Crown Copyright.

Halmos, P. (1975). The problem of learning to teach. American Mathematical Monthly, 82(5), 466-476.

Jablonka, E. (2003). Mathematical Literacy. In A. J. Bishop, M. A. Clements, C. Keitel, J. Kilpatrick, \& F. K. S. Leung (Eds.), Second international handbook of mathematics education (pp. 75-102). Dordrecht: Kluwer Academic Publisher.

Jansen, J. (2009, January 4). Old school: New system produces the same results. The Sunday Tribune, p. 20.

Maguire, T., \& O'Donoghue, J. (2003). Numeracy concept sophistication - An organizing framework, a useful thinking tool. In J. Maaß \& W. Schlöglmann (Eds.), Proceedings of the 10th International Conference on Adults Learning Mathematics (pp. 154-161). Linz, Austria: ALM and Johannes Kepler Universität.

Department of Education. (2003). National curriculum statement Grades 10-12. (General): Mathematical Literacy. Pretoria: Department of Education.

Department of Education. (2007). National curriculum statement Grades 10-12 (General): Subject Assessment Guidelines. Mathematical Literacy. Pretoria: Department of Education.

Organisation for Economic Cooperation and Development. (2003). The PISA 2003 assessment framework Mathematics, Reading, Science and problem-solving knowledge and skills. Paris: Organisation for Economic Cooperation and Development.

Olkin, I., \& Schoenfeld, A. H. (1994). A discussion of Bruce Reznick's chapter. In A. H. Schoenfeld (Ed.), Mathematical thinking and problem solving (pp. 39-51). Hillsdale, NJ: Lawrence Erlbaum Associates.

Polya, G. (1962). Mathematical discovery: On understanding, learning and teaching problem-solving. New York: Wiley.

Presmeg, N. (1986). Visualisation in high school mathematics. For the Learning of Mathematics, 6(3), 42-46. 
Prince, R., Frith, V., \& Burgoyne, N. (2008, August). Mathematical Literacy - Grade 11 and 12 exemplars. Paper presented at the South African Mathematics Society Workshop. Pretoria.

Qualifications and Curriculum Development Agency (2007). Functional skills standards. London: Qualifications and Curriculum Development Agency. Available at http://orderline.qcda.gov.uk/gempdf/ 1847215955.pdf.

Scribner, S. (1984). Studying working intelligence. In B. Rogoff \& J. Lave (Eds.), Everyday cognition: Its development in social context. Cambridge, MA: Harvard University Press.

Steen, L. A. (2001). The case for quantitative literacy. In L. A. Steen (Eds.), Mathematics and democracy. The case for quantitative literacy (pp. 1-22). Washington, DC: The Mathematical Association of America. Available from http://www.maa.org/ql/mathanddemocracy.html.

Umalusi. (2009). 2008 Maintaining standards report. From NATED 550 to the new national curriculum: Maintaining standards in 2008. Pretoria: Umalusi.

Venkat, H., Graven, M., Lampen, E., Nalube, P., \& Chitera, N. (2009). Reasoning and reflecting in Mathematical Literacy. Learning and Teaching Mathematics, 7, 47-53. Available from http:/www.sun.ac.za/ mathed/AMESA/amesal_n7_a13.pdf. 